\title{
Common-Mode Reduction SVPWM for Three-Phase Motor Fed by Two-Level Voltage Source Inverter
}

\author{
Jian Zheng ${ }^{1(\mathbb{D},}$, Mingcheng Lyu ${ }^{2}$, Shengqing $\mathrm{Li}^{1, *}$, Qiwu Luo ${ }^{3} \mathbb{C}$ and Keyuan Huang ${ }^{2}$ \\ 1 College of Electrical \& Information Engineering, Hunan University of Technology, Zhuzhou 412007, China; \\ zj11660@hut.edu.cn \\ 2 College of Electrical \& Information Engineering, Hunan University, Changsha 410082, China; \\ lmc2016@hnu.edu.cn (M.L.); kyhuang@163.com (K.H.) \\ 3 School of Automation, Central South University, Changsha 410083, China; luoqiwu@csu.edu.cn \\ * Correspondence: 1sq1961@sohu.com; Tel.: +86-135-7429-4829
}

Received: 14 May 2020; Accepted: 19 June 2020; Published: 30 July 2020

\begin{abstract}
Aiming at the problem of large magnitude and high frequency of common-mode voltage (CMV) when space vector pulse width modulation (SVPWM) is used in a three-phase motor fed by a two-level voltage source inverter, a common-mode reduction SVPWM (CMRSVPWM) is studied. In this method, six new sectors are obtained by rotating six sectors of conventional SVPWM by $30^{\circ}$. In odd-numbered sectors, only three non-zero vectors with odd subscripts are used for synthesis, while in even-numbered sectors, only three non-zero vectors with even subscripts are used for synthesis. The actuation durations of three non-zero vectors in each switching period in each sector are given. Simulation and experimental results show that, compared with the conventional SVPWM, the CMV magnitude of CMRSVPWM is reduced by $66.67 \%$ and the CMV frequency of CMRSVPWM is reduced from the original switching frequency to the triple fundamental frequency. At the same time, the current, torque and speed of the motor are still good.
\end{abstract}

Keywords: common-mode voltage (CMV); space vector pulse width modulation (SVPWM); three-phase motor; two-level voltage source inverter

\section{Introduction}

It is well known that the use of AC drives can achieve high efficiency and energy saving [1]. In AC drives, a three-phase motor fed by a two-level voltage source inverter has found widespread application [2]. At present, the dominant control strategy of the voltage source inverter is pulse width modulation (PWM) strategy. Among all the PWM methods, the space vector PWM (SVPWM) method is an advanced method due to its superior performance characteristics [3]. However, the conventional SVPWM has the problem of large magnitude and high frequency of common-mode voltage (CMV) [4]. The CMV magnitude is equal to $U_{\mathrm{dc}} / 2$ ( $U_{\mathrm{dc}}$ is the DC bus voltage value of the inverter), and the CMV frequency is equal to the switching frequency of the inverter, from several $\mathrm{kHz}$ to tens of $\mathrm{kHz}[5]$. The CMV with large magnitude and high frequency brings adverse effects on the drive system, such as winding insulation deterioration, shaft voltage, leakage current, electromagnetic interference, etc., and therefore in high-performance AC drives it is necessary to reduce the CMV [6-8].

The methods for reducing the CMV focus on hardware and software: the hardware methods are mainly to add a filter or an inverter leg, and the software methods are mainly to adopt improved modulation strategy [9-12]. The software methods do not increase the cost from hardware, and can reduce the burden of the filter. Therefore, they have excellent price performance, and are widely concerned in academia and industry $[13,14]$. In the software methods, it is an important research idea to improve the conventional SVPWM, which has been studied by some scholars [15-17]. For example, 
a previous paper [15] presents an "active zero state PWM (AZSPWM)" method on the basis of the conventional SVPWM. In this method, null vectors are no longer used, but some equivalent null vectors are used instead of those original null vectors. Two non-zero vectors in the opposite direction are used for synthesis, and the synthetic result is a zero vector, which is called an equivalent null vector or an active zero vector. The method introduced in a previous paper [16] is the "near state PWM (NSPWM)" method. In this method, null vectors are not used either. In each sector, in addition to using two non-zero vectors located in the sector, a non-zero vector located in the left adjacent sector or the right adjacent sector is also used to participate in synthesis. Therefore, the feature of the method is that three non-zero vectors closest to a reference vector are used for synthesis, and the synthetic result can track the reference vector. In the paper [17], a "virtual space vector modulation (VSVM)" method is presented. In each sector, two virtual non-zero vectors and two real non-zero vectors are used for synthesis. The feature of the method is that four non-zero vectors closest to the reference vector are used for synthesis. In the above SVPWM methods, the CMV magnitude can be reduced from the original $U_{\mathrm{dc}} / 2$ to $U_{\mathrm{dc}} / 6$, that is, reduced by $66.67 \%$. However, the CMV frequency has not been reduced and is still equal to or close to the switching frequency of the inverter. What is more, some harmonic components of the CMV increase slightly [18]. If the frequency of these harmonic components is close to the common-mode resonance frequency of the system, the corresponding common-mode current will be significantly amplified, which is dangerous for system reliability.

Aiming at the shortcomings of the above SVPWM methods, this paper studies a common-mode reduction SVPWM (CMRSVPWM), which can not only reduce the CMV magnitude, but also reduce the CMV frequency. The correctness and validity of the method are verified by simulations and experiments.

\section{Common-Mode Reduction SVPWM}

\subsection{Common-Mode Voltage Values of Eight Basic Vectors}

The system of a three-phase motor fed by a two-level voltage source inverter is shown in Figure 1. The motor may be an asynchronous motor or a synchronous motor, therefore, only the stator winding is shown in Figure 1 while the asynchronous rotor or synchronous rotor is not. This does not affect our research, because the SVPWM is applicable to both the asynchronous motor and the synchronous motor.

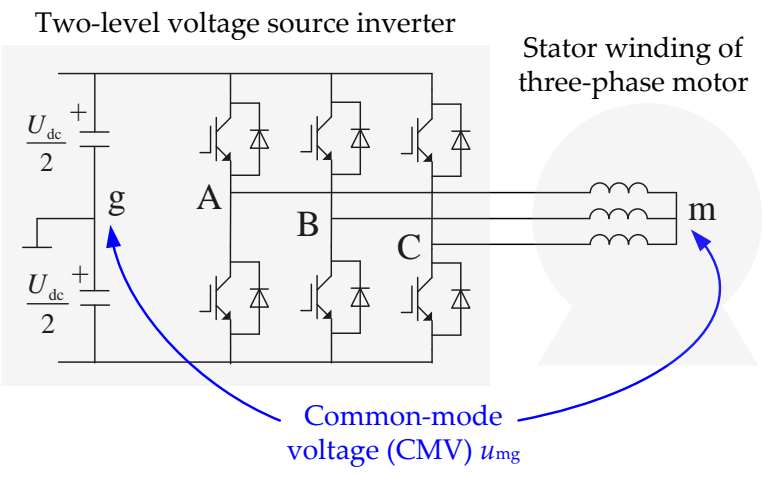

Figure 1. The system of a three-phase motor fed by a two-level voltage source inverter.

The voltage $u_{\mathrm{mg}}$ between the star point $\mathrm{m}$ of the stator winding and the neutral point $\mathrm{g}$ of the inverter DC bus is the CMV, which can be calculated by the following formula [19].

$$
u_{\mathrm{mg}}=\frac{1}{3}\left(u_{\mathrm{Ag}}+u_{\mathrm{Bg}}+u_{\mathrm{Cg}}\right)
$$

where $u_{\mathrm{Ag}}$ refers to the voltage between the midpoint A of the inverter A-phase leg and the neutral point $\mathrm{g}$ of the inverter DC bus, and the meanings of $u_{\mathrm{Bg}}$ and $u_{\mathrm{Cg}}$ are similar to $u_{\mathrm{Ag}}$. 
Because the waveforms of $u_{\mathrm{Ag}}, u_{\mathrm{Bg}}$ and $u_{\mathrm{Cg}}$ are PWM waveforms, the CMV waveform consists of many pulses. The shapes of these pulses are not exactly the same. The CMV magnitude refers to the maximum absolute value of these pulses, and the CMV frequency refers to the pulse-repetition frequency of these pulses, that is, the number of pulses per second.

The inverter has eight switching states, corresponding to eight basic vectors, which are labeled $V_{0}$ to $V_{7}$ in Figure 2a where $V_{0}$ and $V_{7}$ are null vectors and the other six are non-zero vectors. According to (1), the CMV $u_{\mathrm{mg}}$ of these eight basic vectors can be calculated. The values have $-U_{\mathrm{dc}} / 2,-U_{\mathrm{dc}} / 6$, $U_{\mathrm{dc}} / 6, U_{\mathrm{dc}} / 2$ four species, as shown in Table 1 . It can be seen from Table 1 that the CMV magnitude of the null vector $V_{0}$ or $V_{7}$ is the largest, thus null vectors should be avoided in order to reduce the CMV magnitude.

Table 1. Common-mode voltage values of eight basic vectors.

\begin{tabular}{cccccccc}
\hline$V_{0}$ & $V_{1}$ & $V_{2}$ & $V_{3}$ & $V_{4}$ & $V_{5}$ & $V_{6}$ & $V_{7}$ \\
\hline$-U_{\mathrm{dc}} / 2$ & $-U_{\mathrm{dc}} / 6$ & $U_{\mathrm{dc}} / 6$ & $-U_{\mathrm{dc}} / 6$ & $U_{\mathrm{dc}} / 6$ & $-U_{\mathrm{dc}} / 6$ & $U_{\mathrm{dc}} / 6$ & $U_{\mathrm{dc}} / 2$ \\
\hline
\end{tabular}

\subsection{SVPWM by Only Using Three Non-Zero Vectors}

In the conventional SVPWM, the $\alpha-\beta$ plane is divided into six sectors with six non-zero vectors as boundary, which are labeled S1 to S6 in Figure 2a [20]. In each sector, three vectors are used for voltage-second synthesis: the non-zero vector located at the beginning boundary of the sector, the non-zero vector located at the end boundary of the sector, and the null vectors $V_{0}$ or $V_{7}$. Due to the use of null vectors, the CMV magnitude is up to $U_{\mathrm{dc}} / 2$. In comparison, in the AZSPWM, NSPWM, and VSVM, the null vectors are no longer used, therefore the CMV magnitude is reduced to $U_{\mathrm{dc}} / 6$. However, although the CMV magnitude decreases, the CMV frequency does not decrease which is still almost as high as the switching frequency of the inverter.

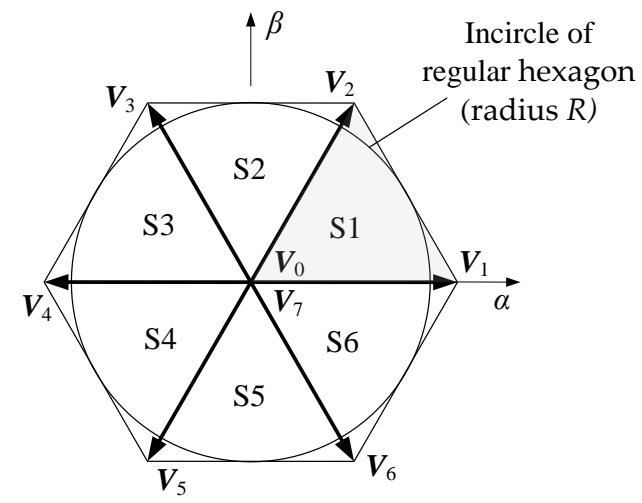

(a)

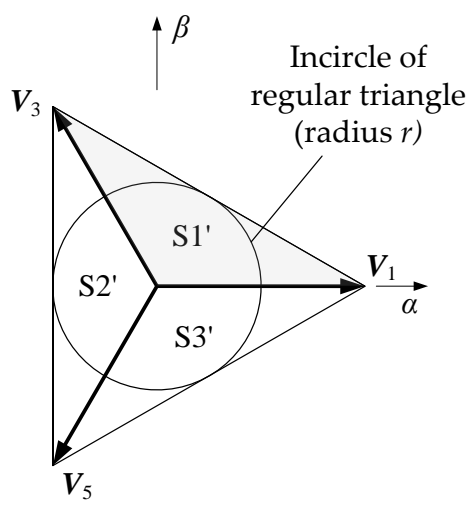

(b)

Figure 2. Conventional SVPWM and SVPWM by only using three non-zero vectors. (a) Conventional SVPWM; (b) SVPWM by only using three non-zero vectors.

It can be seen from Table 1 that the CMV values of $V_{1}, V_{3}$ and $V_{5}$ are all $-U_{\mathrm{dc}} / 6$. Therefore, if only these three non-zero vectors are used for synthesis, the CMV values will remain $-U_{\mathrm{dc}} / 6$ unchanged and the CMV frequency will naturally reduce to zero. This is the so-called SVPWM by only using three non-zero vectors. With $V_{1}, V_{3}$ and $V_{5}$ as the boundary, the $\alpha-\beta$ plane is divided into three sectors, which are labeled $\mathrm{S1}^{\prime}$ to $\mathrm{S}^{\prime}{ }^{\prime}$ in Figure $2 \mathrm{~b}$. Since the three sectors have the same shape, in each sector the voltage-second synthesis is similar. Taking in the sector $\mathrm{S}^{\prime}$ as an example, in a switching period $T_{\mathrm{S}}$, the first actuation vector is the non-zero vector $\boldsymbol{V}_{1}$ located at the beginning boundary of the sector $S 1^{\prime}$, the second actuation vector is the vector $V_{3}$ located at the end boundary of the sector $\mathrm{S}^{\prime}$, and the 
third actuation vector is the remaining vector $V_{5}$. The activation durations $T_{1}, T_{3}$ and $T_{5}$ of these three vectors are calculated by the following voltage-second balance equation [19].

$$
\left\{\begin{array}{l}
T_{1} \boldsymbol{V}_{1}+T_{3} \boldsymbol{V}_{3}+T_{5} \boldsymbol{V}_{5}=T_{\mathrm{s}} \boldsymbol{V}_{\mathrm{ref}} \\
T_{1}+T_{3}+T_{5}=T_{\mathrm{s}}
\end{array}\right.
$$

where $V_{\text {ref }}$ is the reference vector.

By solving (2), we get the following formula [19].

$$
\left\{\begin{array}{l}
T_{1}=\left(\frac{1}{3}+\frac{2}{3} \frac{V_{\text {ref }}}{V} \cos \theta\right) \cdot T_{\mathrm{s}} \\
T_{3}=\left(\frac{1}{3}+\frac{2}{3} \frac{V_{\text {ref }}}{V} \cos \left(\theta-120^{\circ}\right)\right) \cdot T_{\mathrm{S}} \\
T_{5}=T_{\mathrm{s}}-T_{1}-T_{2}
\end{array}\right.
$$

where $V_{\text {ref }}$ is the magnitude of the reference vector; $\theta$ is the position of the reference vector, i.e., the angle between the reference vector and the beginning boundary of the sector, $0^{\circ} \leq \theta \leq 120^{\circ} ; V$ is the magnitude of the non-zero vector.

Similarly, only three non-zero vectors, $V_{2}, V_{4}$ and $V_{6}$, can be used for synthesis. In this case, the $\mathrm{CMV}$ values remain $U_{\mathrm{dc}} / 6$ unchanged and the $\mathrm{CMV}$ frequency is zero.

\subsection{Common-Mode Reduction SVPWM}

The above SVPWM by only using three non-zero vectors can reduce the CMV magnitude to $U_{\mathrm{dc}} / 6$ and the CMV frequency to zero, but the maximum linear output voltage is very small, which is equal to the incircle radius $r$ of the regular triangle in Figure 2b. While the maximum linear output voltage of the conventional SVPWM is equal to the incircle radius $R$ of the regular hexagon in Figure $2 \mathrm{a}$. After calculation, $r=0.57735 R$.

In order to increase the maximum linear output voltage, the SVPWM by only using $V_{1}, V_{3}, V_{5}$ and the SVPWM by only using $V_{2}, V_{4}, V_{6}$ are combined to form the common-mode reduction SVPWM (CMRSVPWM). The $\alpha-\beta$ plane is divided into new six sectors, which are labeled S1" to S6" in Figure 3a. Comparing the six sectors in Figure 3a with those in Figure 2a, we can see that by turning the six sectors of conventional SVPWM anticlockwise by $30^{\circ}$, new six sectors are get. In odd-numbered sectors S1", S3", S5", three non-zero vectors with odd subscripts $V_{1}, V_{3}, V_{5}$ are used for synthesis, while in even-numbered sectors S2", S4", S6", three non-zero vectors with even subscripts $V_{2}, V_{4}, V_{6}$ are used for synthesis. The activation durations of three non-zero vectors in each switching period in each sector are similar to (3).

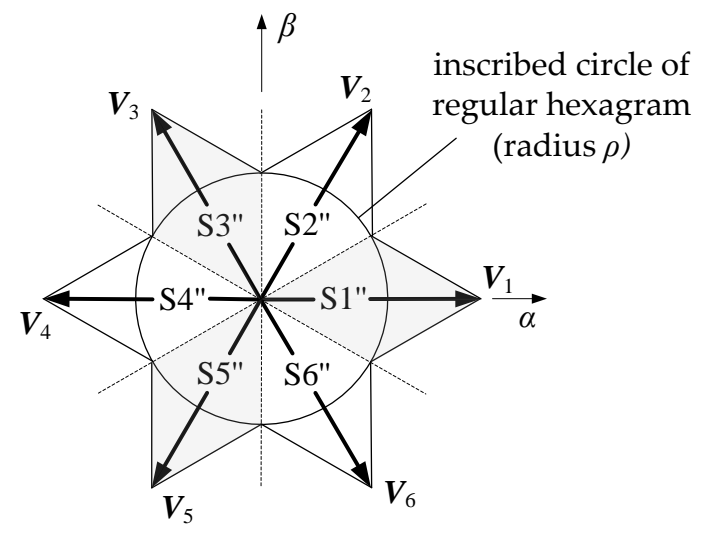

(a)

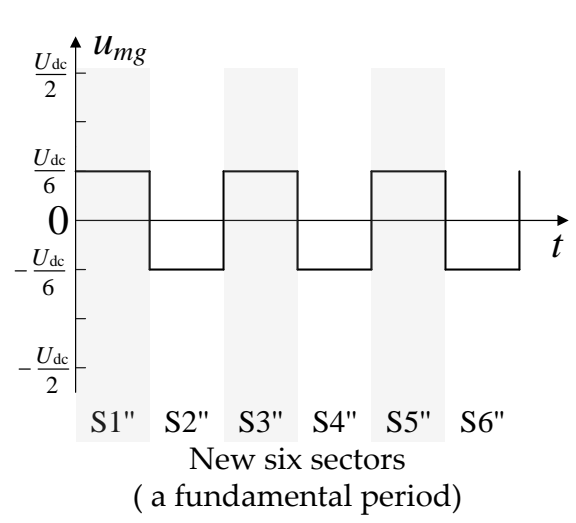

(b)

Figure 3. Common-mode reduction SVPWM and common-mode voltage waveform. (a) Common-mode reduction SVPWM; (b) Common-mode voltage waveform in a fundamental period. 
To better explain this point, we might as well modify (3) a little to make it universal. Let us record the first actuation vector as $V_{x}$, the second actuation vector as $V_{y}$, and the third actuation vector as $V_{z}$. The activation durations of the three vectors $V_{x}, V_{y}$ and $V_{z}$ are respectively $T_{x}, T_{y}$ and $T_{z}$, and from (3) we get the following formula.

$$
\left\{\begin{array}{l}
T_{x}=\left(\frac{1}{3}+\frac{2}{3} \frac{V_{\text {ref }}}{V} \cos \theta\right) \cdot T_{\mathrm{s}} \\
T_{y}=\left(\frac{1}{3}+\frac{2}{3} \frac{V_{\text {ref }}}{V} \cos \left(\theta-120^{\circ}\right)\right) \cdot T_{\mathrm{s}} \\
T_{z}=T_{\mathrm{s}}-T_{x}-T_{y}
\end{array}\right.
$$

where $V_{\text {ref, }} \theta$, and $V$ have the same meaning as (3).

When the reference vector $V_{\text {ref }}$ is located in different sectors, the non-zero vectors corresponding to the first vector $V_{x}$, the second vector $V_{y}$ and the third vector $V_{z}$ are shown in Table 2 .

Table 2. Three actuation vectors in each sector.

\begin{tabular}{ccccc}
\hline & Sectors & The First Vector $V_{x}$ & The Second Vector $V_{y}$ & The Third Vector $V_{z}$ \\
\hline S1" & $0^{\circ} \leq \theta<30^{\circ}$ & $V_{5}$ & $V_{1}$ & $V_{3}$ \\
& $30^{\circ} \leq \theta<60^{\circ}$ & $V_{1}$ & $V_{3}$ & $V_{5}$ \\
S2" & $0^{\circ} \leq \theta<30^{\circ}$ & $V_{6}$ & $V_{2}$ & $V_{4}$ \\
& $30^{\circ} \leq \theta<60^{\circ}$ & $V_{2}$ & $V_{4}$ & $V_{6}$ \\
S3" $^{\circ}$ & $0^{\circ} \leq \theta<30^{\circ}$ & $V_{1}$ & $V_{3}$ & $V_{5}$ \\
& $30^{\circ} \leq \theta<60^{\circ}$ & $V_{3}$ & $V_{5}$ & $V_{1}$ \\
S4" & $0^{\circ} \leq \theta<30^{\circ}$ & $V_{2}$ & $V_{4}$ & $V_{6}$ \\
& $30^{\circ} \leq \theta<60^{\circ}$ & $V_{4}$ & $V_{6}$ & $V_{2}$ \\
S5 $^{\prime \prime}$ & $0^{\circ} \leq \theta<30^{\circ}$ & $V_{3}$ & $V_{5}$ & $V_{3}$ \\
& $30^{\circ} \leq \theta<60^{\circ}$ & $V_{5}$ & $V_{1}$ & $V_{2}$ \\
S6 $^{\prime \prime}$ & $0^{\circ} \leq \theta<30^{\circ}$ & $V_{4}$ & $V_{6}$ & $V_{4}$ \\
\hline
\end{tabular}

The maximum linear output voltage of CMRSVPWM is equal to the inscribed circle radius $\rho$ of the regular hexagram in Figure 3a. After calculation, $\rho=0.6667 R$, which is $15.47 \%$ larger than $r$. Therefore, the maximum linear output voltage of CMRSVPWM increases by $15.47 \%$.

Figure $3 \mathrm{~b}$ shows the CMV waveform of CMRSVPWM in a fundamental period (i.e., six sectors S1" to $\left.S 6^{\prime \prime}\right)$. The peak value of waveform is $U_{\mathrm{dc}} / 6$ and the valley value is $-U_{\mathrm{dc}} / 6$, which indicates that the CMV magnitude is $U_{\mathrm{dc}} / 6$. The number of pulses in a fundamental period is 3 , which indicates that the CMV frequency is equal to the triple fundamental frequency. Therefore, theoretically, both magnitude and frequency of CMV are reduced.

\section{Simulations and Experiments}

In order to verify the correctness and validity of the CMRSVPWM, we perform simulations and experiments using the CMRSVPWM and the conventional SVPWM and compare their results, taking a three-phase cage induction motor fed by a two-level voltage source inverter as the object.

\subsection{Simulation Results}

The simulation model of the object is created in MATLAB/Simulink. The simulation parameters are shown in Table 3. 
Table 3. Simulation and experiment parameters.

\begin{tabular}{llll}
\hline Parameters & Values & Parameters & Values \\
\hline Inverter DC bus voltage & $540 \mathrm{~V}$ & Motor stator resistance & $4.26 \Omega$ \\
Inverter switching frequency & $10 \mathrm{kHz}$ & Motor rotor resistance & $3.24 \Omega$ \\
SVPWM reference vector & $180 \mathrm{~V} / 29 \mathrm{~Hz}$ & Motor stator inductance & $0.666 \mathrm{H}$ \\
Motor rated power & $1.5 \mathrm{~kW}$ & Motor rotor inductance & $0.67 \mathrm{H}$ \\
Motor rated voltage & $380 \mathrm{~V} / 50 \mathrm{~Hz}$ & Motor mutual inductance & $0.651 \mathrm{H}$ \\
Motor moment of inertia & $0.02 \mathrm{~kg} \cdot \mathrm{m}^{2}$ & Motor number of pole pairs & 2 \\
\hline
\end{tabular}

The motor is controlled by using constant Volt/Hz, without considering automatic speed regulator, automatic torque regulator or automatic current regulator, so as to focus on the characteristics of SVPWM algorithm. The simulation process is as follows: the motor is started under no-load at $0 \mathrm{~s}$; a $8.84 \mathrm{~N} \cdot \mathrm{m}$ load torque is applied at $0.4 \mathrm{~s}$; the simulation stops at $0.8 \mathrm{~s}$. The CMV simulation waveforms and their fast Fourier transform (FFT) analysis in the two methods are shown in Figure 4.
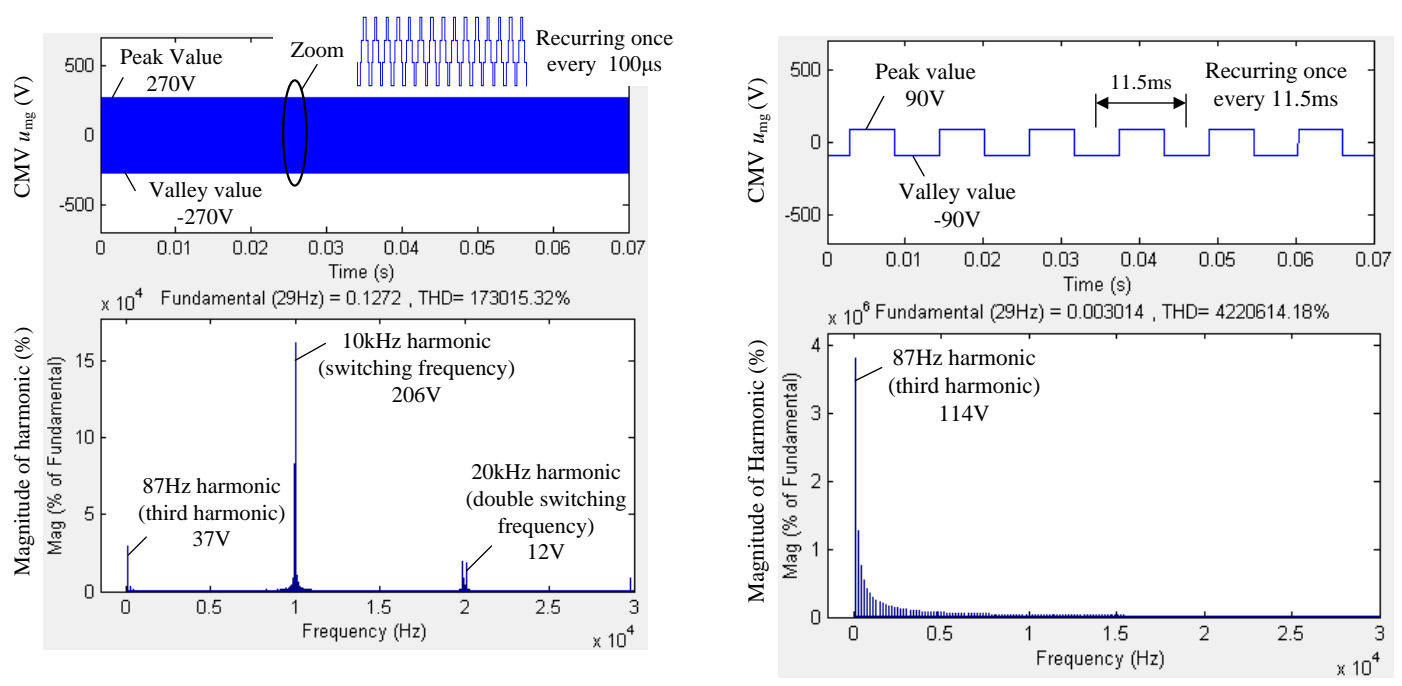

(a)

(b)

Figure 4. Common-mode voltage simulation waveforms and their FFT analysis in two methods. (a) Conventional SVPWM; (b) CMRSVPWM.

Upon comparison of Figure $4 \mathrm{a}, \mathrm{b}$ we find that the CMV peak value and CMV valley value in the conventional SVPWM are $270 \mathrm{~V}$ and $-270 \mathrm{~V}$ respectively, while those in the CMRSVPWM are $90 \mathrm{~V}$ and $-90 \mathrm{~V}$ respectively. Therefore, the former has a CMV magnitude of $270 \mathrm{~V}$, i.e., $U_{\mathrm{dc}} / 2$, while the latter has a CMV magnitude of $90 \mathrm{~V}$, i.e., $U_{\mathrm{dc}} / 2$, which reduces the magnitude by $66.67 \%$. This is because the former uses null vectors while the latter does not. These simulation results are consistent with the theoretical analysis.

In the upper right corner of Figure $4 a$, a CMV zoom figure is shown. Inspection of the figure indicates that the pulse of CMV waveform recurs once every $100 \mu \mathrm{s}$, which indicates the frequency is $10 \mathrm{kHz}$ that equals the switching frequency of the inverter. While from Figure $4 \mathrm{~b}$ it is apparent that the pulse of CMV waveform recurs once every $11.5 \mathrm{~ms}$, which indicates the frequency is $87 \mathrm{~Hz}$ that equals the triple fundamental frequency (the fundamental frequency refers to that of the inverter output voltage, that is, the reference vector rotation frequency), far less than the switching frequency of the inverter.

According to the FFT analysis in Figure 4, both methods have certain third harmonic component in the CMV waveform, but because the star point of stator winding is isolated, the third harmonic current 
will not be generated. In addition, the conventional SVPWM has larger $10 \mathrm{kHz}$ harmonics and a certain $20 \mathrm{kHz}$ harmonics in the CMV waveform, while the CMRSVPWM has no high frequency harmonics.

The stator A-phase voltage simulation waveforms, their FFT analysis, and their waveforms after low-pass filtering (LPF) in two methods are shown in Figure 5.
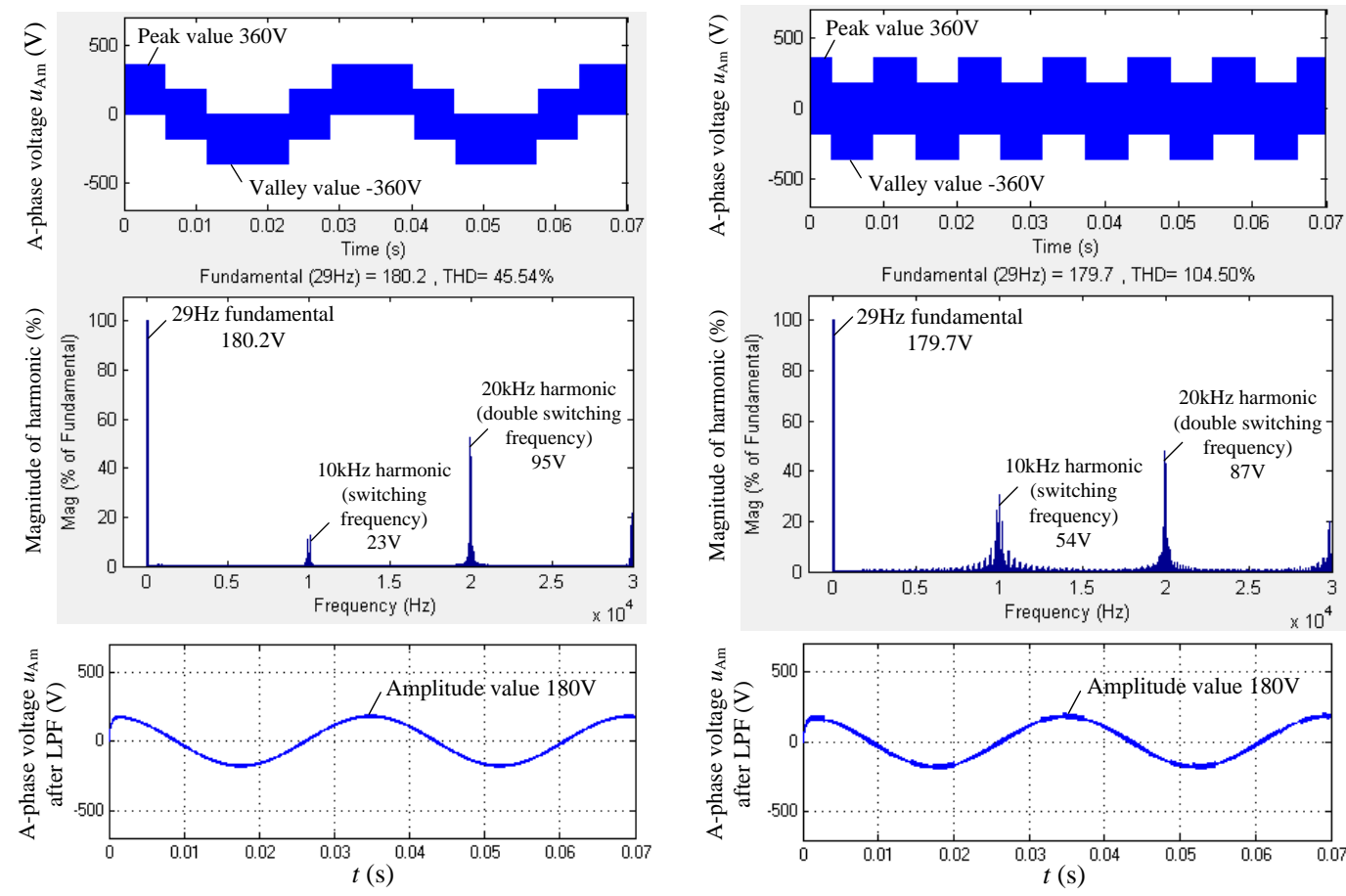

(a)

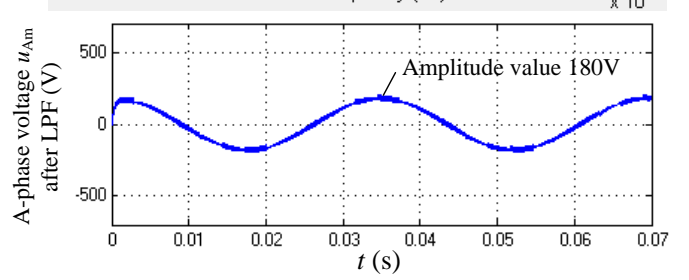

(b)

Figure 5. Stator A-phase voltage simulation waveforms, their FFT analysis, and their waveforms after low-pass filtering (LPF) in two methods. (a) Conventional SVPWM; (b) CMRSVPWM.

Comparing the FFT analysis of Figure 5a,b, we can see that the fundamental $(29 \mathrm{~Hz})$ amplitudes of A-phase voltage in the two methods are $180.2 \mathrm{~V}$ and $179.7 \mathrm{~V}$ respectively, which is consistent with the theoretical value of $180 \mathrm{~V}$. The total harmonic distortion (THD) for A-phase voltage in the CMRSVPWM is higher than that in the conventional SVPWM, which is due to the A-phase voltage waveform symmetry in the CMRSVPWM is slightly lower than that in the conventional SVPWM in each switching period. Comparing the A-phase voltage $u_{\text {Am }}$ after LPF of Figure $5 \mathrm{a}, \mathrm{b}$, we can see that the waveforms in the two methods are basically the same, both of which are sine waves with an amplitude of $180 \mathrm{~V}$. Therefore, the winding voltages in the two methods are basically the same in the low frequency band, only different in the high frequency band.

Under the supply of the winding voltages, the simulation results of stator flux, stator currents, electromagnetic torque and rotor speed are basically the same in the two methods, as shown in Figure 6. This is because the stator windings are inductive load and the rotors have rotational inertia, even if the winding voltages in the two methods are different in the high frequency band, the responses in the two methods will be identical as long as both the winding voltages are identical in the low frequency band. 


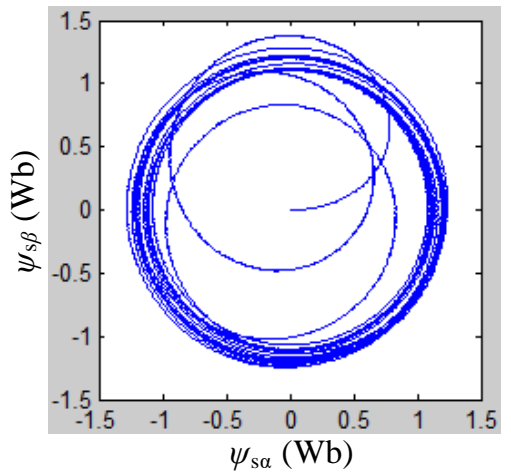

(a)

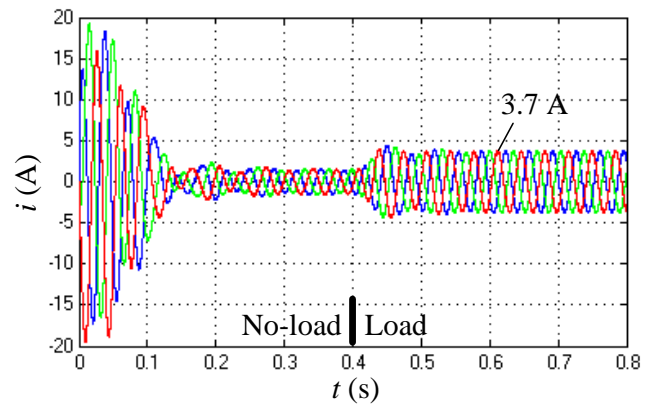

(c)

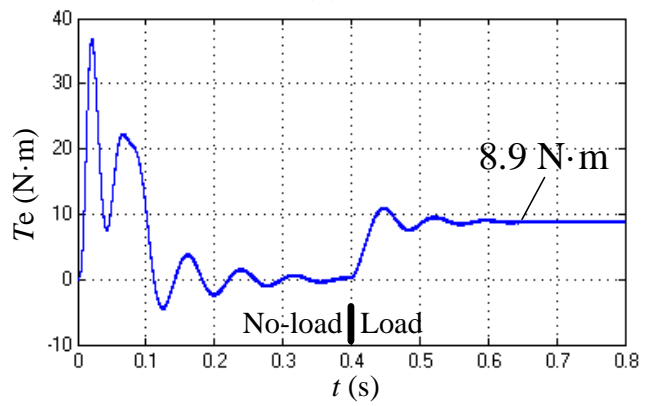

(e)

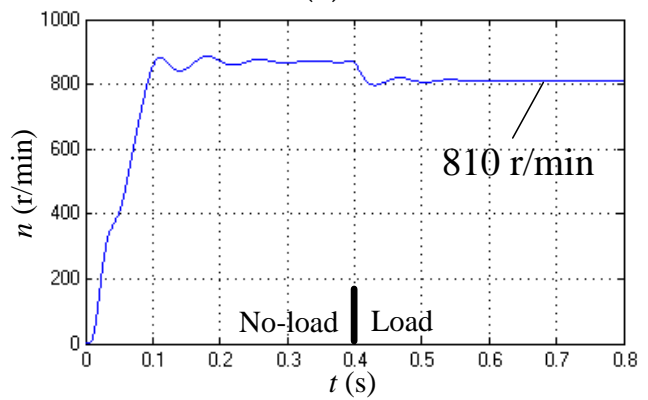

(g)

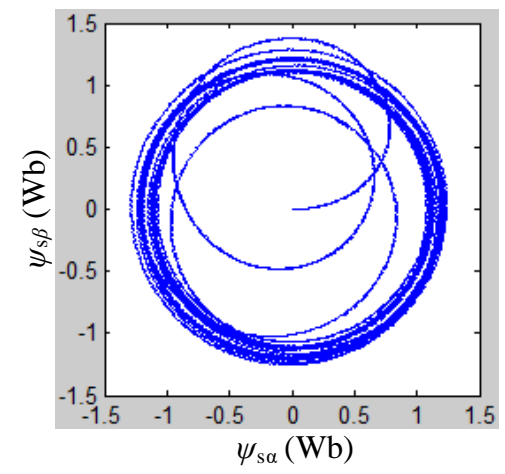

(b)

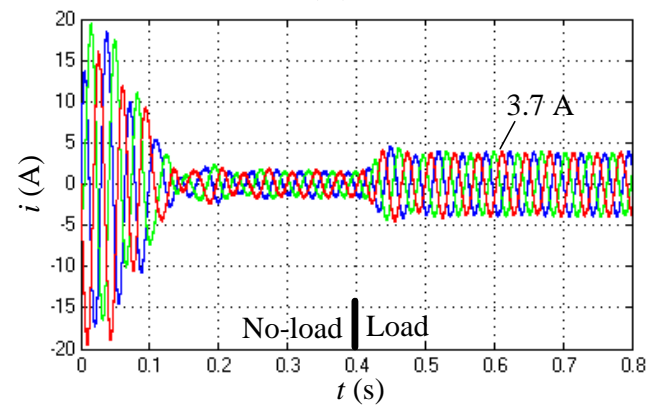

(d)

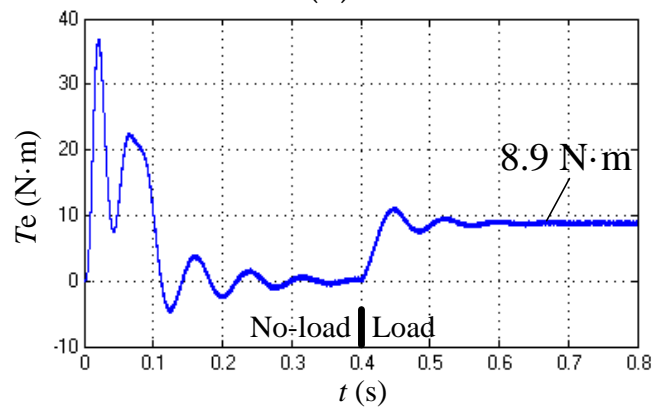

(f)

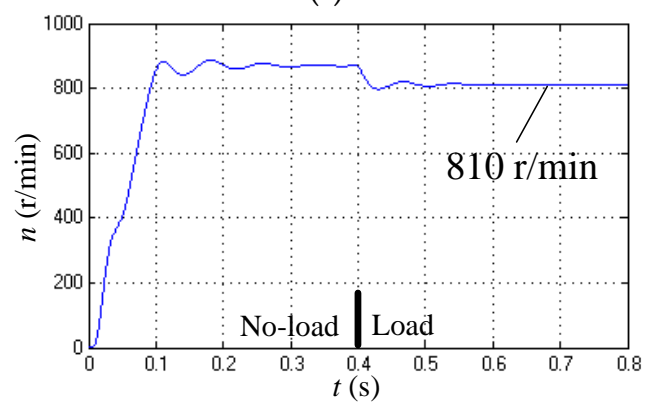

(h)

Figure 6. Simulation waveforms of flux, current, torque and speed in two methods. (a) Stator flux trajectory in conventional SVPWM; (b) Stator flux trajectory in CMRSVPWM; (c) Stator currents in conventional SVPWM; (d) Stator currents in CMRSVPWM; (e) Electromagnetic torque in conventional SVPWM; (f) Electromagnetic torque in CMRSVPWM; (g) Rotor speed in conventional SVPWM; (h) Rotor speed in CMRSVPWM.

The simulation results above show that the CMRSVPWM can effectively reduce the magnitude and frequency of $\mathrm{CMV}$, while other performance indexes have not declined, which is basically the same as the conventional SVPWM. 


\subsection{Experimental Results}

The experiment parameters are the same as the simulation parameters, shown in Table 3. The motor is also controlled by using constant Volt $/ \mathrm{Hz}$. The experimental process is similar to the simulation process: the motor is started under no-load at $0 \mathrm{~s}$; a $8.84 \mathrm{~N} \cdot \mathrm{m}$ load torque is applied at $40 \mathrm{~s}$; the experiment stops at $80 \mathrm{~s}$. The inverter DC bus of the experimental device is composed of two identical capacitors in series, as shown in Figure 1. The voltage between the midpoint $g$ of two series capacitors and the star point $\mathrm{m}$ of the stator winding measured by a high-voltage differential probe of the oscilloscope is the CMV. The CMV experimental waveforms and their FFT analysis in the two methods are shown in Figure 7.

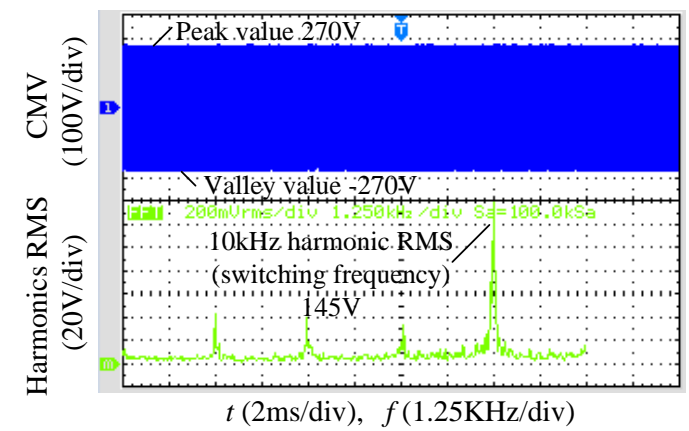

(a)

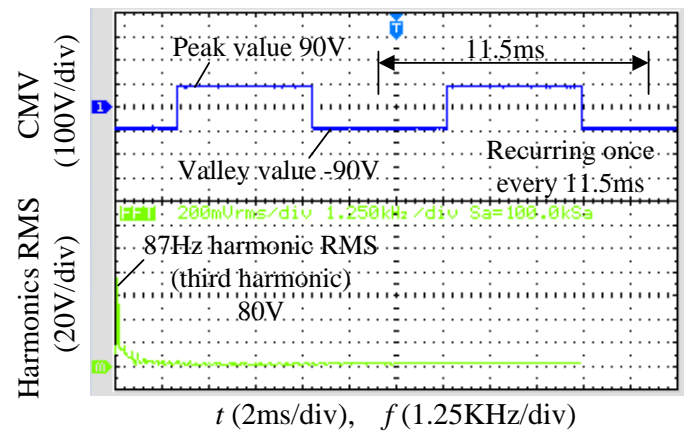

(b)

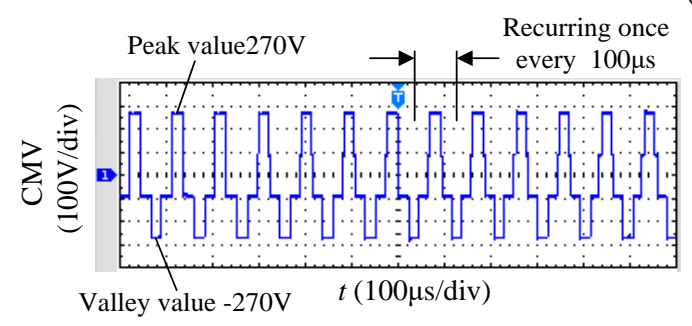

(c)

Figure 7. Common-mode voltage experimental waveforms and their FFT analysis in two methods. (a) Conventional SVPWM; (b) CMRSVPWM; (c) Conventional SVPWM (zoom).

Comparing the CMV waveforms of Figure $7 \mathrm{a}, \mathrm{b}$, we can see that the peak values and the valley values in the two methods are consistent with the simulation results. Comparison of their FFT analysis show that the CMV in the conventional SVPWM has high-frequency harmonics, of which $10 \mathrm{kHz}$ harmonics root-mean-square (RMS for short in Figure 7) is large; while the CMV in the CMRSVPWM has almost no high-frequency harmonics. Figure 7c shows a horizontal magnification of Figure $7 \mathrm{a}$. The diagram shows that the pulse of CMV waveform recurs once every $100 \mu \mathrm{s}$, which means the frequency is $10 \mathrm{kHz}$. While Figure $7 \mathrm{~b}$ shows that the pulse of CMV waveform recurs once every $11.5 \mathrm{~ms}$, accordingly, the frequency is $87 \mathrm{~Hz}$ that is only three times as much as the reference vector rotation frequency.

The experimental waveforms of stator line voltage after low-pass filtering (LPF), stator phase current, electromagnetic torque and rotor speed in the two methods are basically the same, as shown in Figure 8. 


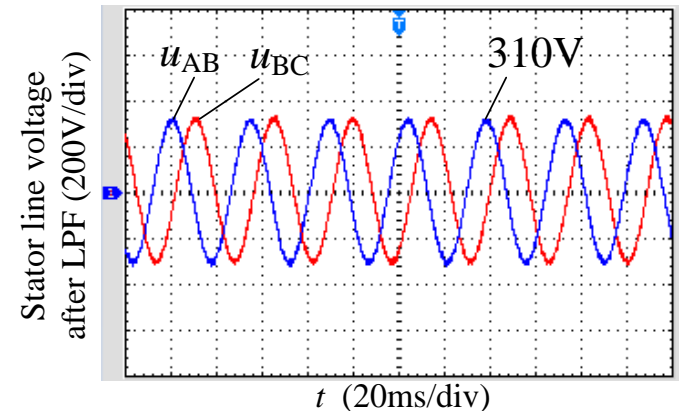

(a)

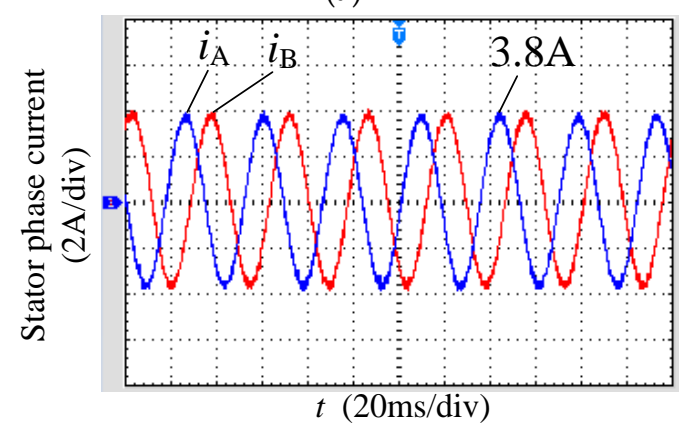

(c)

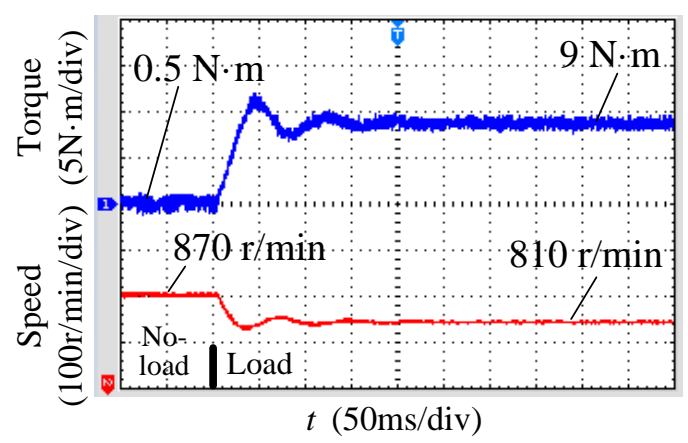

(e)

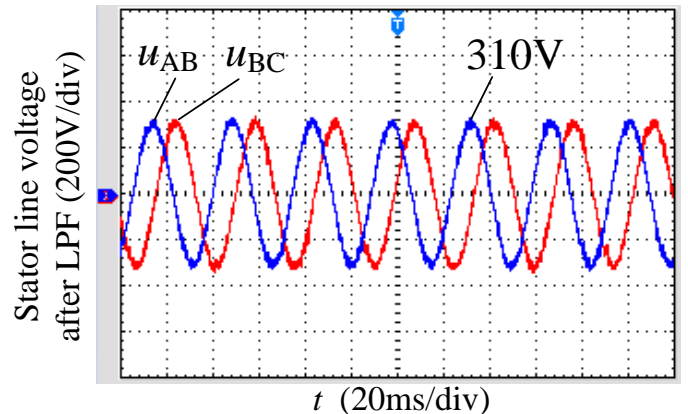

(b)

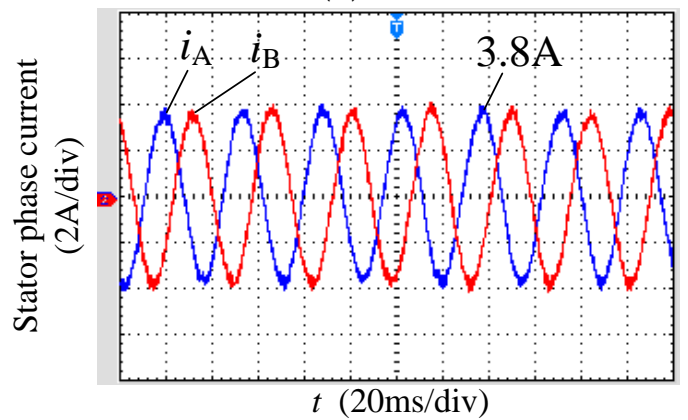

(d)

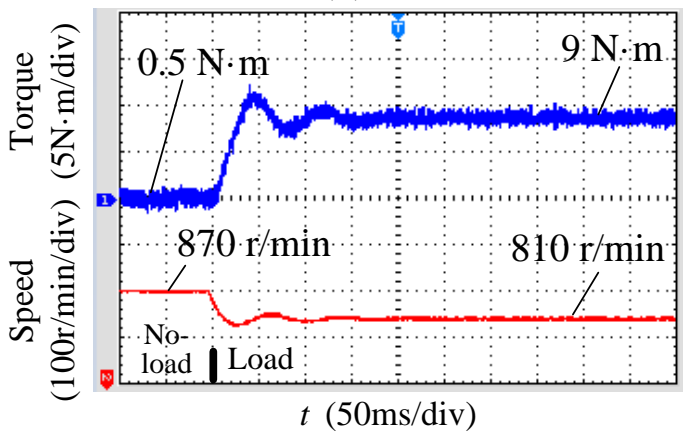

(f)

Figure 8. Experimental waveforms of stator line voltage after low-pass filtering (LPF), stator phase current, electromagnetic torque and rotor speed in the two methods. (a) Stator line voltage after LPF in conventional SVPWM; (b) Stator line voltage after LPF in CMRSVPWM; (c) Stator phase current in conventional SVPWM; (d) Stator phase current in CMRSVPWM; (e) Electromagnetic torque and rotor speed in conventional SVPWM; (f) Electromagnetic torque and rotor speed in CMRSVPWM.

Figure $8 \mathrm{a}, \mathrm{b}$ show the stator line voltages $u_{\mathrm{AB}}$ and $u_{\mathrm{BC}}$ after LPF in two methods. They are all sine waves with an amplitude of about $310 \mathrm{~V}$, a frequency of $29 \mathrm{~Hz}$, a phase difference of $120^{\circ}$. There is no low-order harmonic such as $3 \mathrm{rd}, 5 \mathrm{th}, 7 \mathrm{th}$. Figure $8 \mathrm{c}, \mathrm{d}$ show the stator phase current $i_{\mathrm{A}}$ and $i_{\mathrm{B}}$ in steady state after loading in two methods. They are all sine waves with an amplitude of about $3.8 \mathrm{~A}$, a frequency of $29 \mathrm{~Hz}$, a phase difference of $120^{\circ}$. There is also no low-order harmonic such as 3rd, 5 th, 7 th. Figure $8 \mathrm{e}, \mathrm{f}$ show the electromagnetic torque and rotor speed before and after loading in two methods. The transition process is about $150 \mathrm{~ms}$, and the steady state torque and steady state speed are very stable. In addition, due to the open-loop experiments, there is a speed drop, and a speed feedback control can reduce or eliminate the speed drop.

It is worth pointing out that in the speed feedback control system, using SVPWM based on model predictive control (MPC) to reduce the CMV is an important method, which is suitable for both voltage source inverters and current source inverters [12,14,21]. In addition, it is also the important methods for CMV reduction to modify the traditional selected harmonic elimination PWM (SHEPWM) and the 
traditional sinusoidal PWM (SPWM) [22,23]. Table 4 provides a feature summary of five PWM methods: virtual space vector modulation (VSVM) [17], CMRSVPWM studied in this paper, model prediction control SVPWM (MPC-SVPWM for short in Table 4) [12], modified SHEPWM [22], and modified SPWM [23]. Performance indexes considered include the CMV magnitude, the CMV frequency, the CMV third harmonic, the maximum linear output voltage, the number of switching in a switching period, the stator phase voltage THD, and the algorithm complexity. It can be seen from Table 4 that all five methods can reduce the CMV magnitude to $U_{\mathrm{dc}} / 6$. The significant advantage of VSVM is that not only the CMV magnitude is reduced but also the CMV third harmonic is eliminated, which helps to reduce the size and cost of the common mode filter, especially in medium voltage electric drives. Another advantage of VSVM is that the number of switching is the least in the five methods, therefore the switching losses are the lowest. The third advantage of VSVM is its low algorithm complexity. The disadvantages of VSVM are that the maximum linear output voltage decreases and the stator phase voltage THD is higher. The advantage of CMRSVPWM lies in its ability to reduce both the CMV magnitude and the CMV frequency. The CMV frequency in CMRSVPWM is only three times the fundamental frequency, while that in other four methods is close to the switching frequency. The disadvantages of CMRSVPWM are that the CMV third harmonic are not eliminated and the maximum linear output voltage is the lowest. To increase the maximum linear output voltage, overmodulation techniques can be tried. The advantages of MPC-SVPWM are that the maximum linear output voltage is the highest and the stator phase voltage THD is the lowest. Its disadvantages are that the CMV third harmonic are not eliminated and the algorithm complexity is higher. In the modified SHEPWM, although the CMV third harmonic can be eliminated through some specified calculation, the algorithm complexity is the highest in the five methods, and the maximum linear output voltage is the lowest. In the modified SPWM, whether the CMV third harmonic can be eliminated depends on the modulation wave, and both the stator phase voltage THD and the algorithm complexity are high.

Table 4. Features of five PWM methods for common-mode reduction.

\begin{tabular}{|c|c|c|c|c|c|}
\hline Performance Indexes & VSVM & CMR-SVPWM & MPC-SVPWM & $\begin{array}{l}\text { Modified } \\
\text { SHEPWM }\end{array}$ & $\begin{array}{l}\text { Modified } \\
\text { SPWM }\end{array}$ \\
\hline CMV magnitude & $U_{\mathrm{dc}} / 6$ & $U_{\mathrm{dc}} / 6$ & $U_{\mathrm{dc}} / 6$ & $U_{\mathrm{dc}} / 6$ & $U_{\mathrm{dc}} / 6$ \\
\hline CMV frequency & $\begin{array}{l}\text { Close to } \\
\text { switching } \\
\text { frequency }\end{array}$ & $\begin{array}{l}\text { Triple } \\
\text { fundament } \\
\text { frequency }\end{array}$ & $\begin{array}{l}\text { Close to } \\
\text { switching } \\
\text { frequency }\end{array}$ & $\begin{array}{l}\text { Close to } \\
\text { switching } \\
\text { frequency }\end{array}$ & $\begin{array}{l}\text { Close to } \\
\text { switching } \\
\text { frequency }\end{array}$ \\
\hline CMV third harmonic & No & Yes & Yes & No & Yes/No \\
\hline $\begin{array}{l}\text { Maximum linear } \\
\text { output voltage }\end{array}$ & $0.8667 R$ & $0.6667 R$ & $R$ & $0.6667 R$ & $0.8667 R$ \\
\hline $\begin{array}{l}\text { Number of switching in a } \\
\text { switching period }\end{array}$ & 6 & 8 & 8 & 8 & 8 \\
\hline Stator phase voltage THD & High & High & Low & Low & High \\
\hline Algorithm complexity & Low & Low & High & High & High \\
\hline
\end{tabular}

The above experimental results show that the CMRSVPWM can reduce the magnitude and frequency of CMV with effect. Meanwhile, the CMRSVPWM can keep as good performance as the conventional SVPWM in line voltage, phase current, electromagnetic torque and rotor speed of the motor. The simulation and experimental results verified the studied CMRSVPWM method.

\section{Conclusions}

In order to reduce the CMV magnitude and the CMV frequency in the three-phase motor fed by the two-level voltage source inverter, the CMRSVPWM is studied, and the simulations and experiments are carried out in this paper. The main conclusions are as follows:

(1) Compared with the conventional SVPWM, the CMV magnitude in the CMRSVPWM is reduced from the original $U_{\mathrm{dc}} / 2$ to $U_{\mathrm{dc}} / 6$, that is, reduced by $66.67 \%$, and the CMV frequency is reduced from the original switching frequency to three times the fundamental frequency. Therefore, both the CMV 
magnitude and the CMV frequency are effectively reduced. While the line voltage, phase current, electromagnetic torque and rotor speed of the motor are still in good performance.

(2) The maximum linear output voltage of the CMRSVPWM is $66.67 \%$ of that of the conventional SVPWM, but increases by $15.47 \%$ compared with the SVPWM by only using three non-zero vectors. The further research on the CMRSVPWM overmodulation will be carried out to improve the maximum voltage output capability.

Author Contributions: Funding acquisition and conceptualization, K.H.; Methodology, J.Z.; Resources, S.L.; Software, Q.L.; Writing - original draft, M.L. All authors have read and agreed to the published version of the manuscript.

Funding: This research was funded by National Natural Science Foundation of China under Project 51777064, 51977072 and National Key Research and Development Program of China under Project 2018 YFB0606005.

Conflicts of Interest: The authors declare no conflict of interest.

\section{References}

1. Wu, B.; Narimni, M. High-Power Converters and AC Drives, 2nd ed.; John Wiley \& Sons: Hoboken, NJ, USA, 2017; pp. 1-4. ISBN 978-1-119-15603-1.

2. Filizadeh, S. Electric Machines and Drives: Principles, Control, Modeling, and Simulation; CRC Press: Boca Raton, FL, USA, 2013; pp. 181-185. ISBN 978-1-439-85807-3.

3. Huang, Y.; $X u$, Y.; Li, Y.; Yang, G.; Zou, J. PWM frequency voltage noise cancelation in three-phase VSI using the novel SVPWM strategy. IEEE Trans. Power Electron. 2018, 10, 8596-8606. [CrossRef]

4. Che, H.; Zhao, H. Review on pulse-width modulation strategies for common-mode voltage reduction in three-phase voltage-source inverters. IET Power Electron. 2016, 14, 2611-2620.

5. Morris, C.T.; Han, D.; Sarlioglu, B. Reduction of common mode voltage and conducted EMI through three-phase inverter topology. IEEE Trans. Power Electron. 2017, 3, 1720-1724. [CrossRef]

6. Han, D.; Lee, W.; Li, S.; Sarlioglu, B. New method for common mode voltage cancellation in motor drives: Concept, realization, and asymmetry influence. IEEE Trans. Power Electron. 2018, 2, 1188-1201. [CrossRef]

7. Jiang, D.; Shen, Z.; Wang, F. Common-mode voltage reduction for paralleled inverters. IEEE Trans. Power Electron. 2018, 5, 3961-3974. [CrossRef]

8. Robles, E.; Fernandez, M.; Ibarra, E.; Andreu, J.; Kortabarria, I. Mitigation of common mode voltage issues in electric vehicle drive systems by means of an alternative AC-decoupling power converter topology. Energies 2019, 17, 3349. [CrossRef]

9. Jayaraman, K.; Kumar, M. Design of passive common-mode attenuation methods for inverter-fed induction motor drive with reduced common-mode voltage PWM technique. IEEE Trans. Power Electron. 2020, 3, 2861-2870. [CrossRef]

10. Takahashi, S.; Ogasawara, S.; Takemoto, M.; Orikawa, K.; Tamate, M. Common-mode voltage attenuation of an active common-mode filter in a motor drive system fed by a PWM inverter. IEEE Trans. Ind. Appl. 2019, 3, 2721-2730. [CrossRef]

11. Huang, Y.; Xu, Y.; Zhang, W.; Zou, J. Hybrid RPWM technique based on modified SVPWM to reduce the PWM acoustic noise. IEEE Trans. Power Electron. 2019, 6, 5667-5674. [CrossRef]

12. Guo, L.; Jin, N.; Gan, C.; Luo, K. Hybrid voltage vector preselection-based model predictive control for two-level voltage source inverters to reduce the common-mode voltage. IEEE Trans. Ind. Electron. 2020, 6, 4680-4691. [CrossRef]

13. Jiang, W.; Wang, P.; Ma, M.; Wang, J.; Li, J.; Li, L.; Chen, K. A novel virtual space vector modulation with reduced common-mode voltage and eliminated neutral point voltage oscillation for neutral point clamped three-level inverter. IEEE Trans. Ind. Electron. 2020, 2, 884-894. [CrossRef]

14. Jin, T.; Guo, J.; Mohamed, M.A.; Wang, M. A novel model predictive control via optimized vector selection method for common-mode voltage reduction of three-phase inverters. IEEE Access. 2019, 7, 95351-95363. [CrossRef]

15. Cetin, N.O.; Hava, A.M. Interaction between the filter and PWM units in the sine filter configuration utilizing three-phase AC motor drives employing PWM inverters. In Proceedings of the IEEE Energy Conversion Congress \& Exposition, Atlanta, GA, USA, 12-16 September 2010; pp. 2592-2599. 
16. Ün, E.; Hava, A.M. A near-state PWM method with reduced switching losses and reduced common-mode voltage for three-phase voltage source inverters. IEEE Trans. Ind. Appl. 2009, 2, 782-793. [CrossRef]

17. Tian, K.; Wang, J.; Wu, B.; Xu, D.; Cheng, Z.; Zargari, N.R. A virtual space vector modulation technique for the reduction of common-mode voltages in both magnitude and third-order component. IEEE Trans. Power Electron. 2016, 1, 839-848. [CrossRef]

18. Huang, J.; Li, K. Suppression of common-mode voltage spectral peaks by using rotation reverse carriers in sinusoidal pulse width modulation three-phase inverters with CFM. IET Power Electron. 2020, 6, 1246-1256. [CrossRef]

19. Zheng, J.; Rong, F.; Li, P.; Huan, S.; He, Y. Six-phase SVPWM with common-mode voltage suppression. IET Power Electron. 2018, 15, 2461-2469. [CrossRef]

20. Abu-Rub, H.; Iqbal, A.; Guzinski, J. High Performance Control of AC Drives with MATLAB/Simulink Models; John Wiley \& Sons: Hoboken, NJ, USA, 2012; pp. 72-78. ISBN 978-0-470-97829-0.

21. Gao, H.; Wu, B.; Xu, D.; Pande, M.; Aguilera, R.P. Common-mode-voltage-reduced model-predictive control scheme for current-source-converter-fed induction motor drives. IEEE Trans. Power Electron. 2017, 6, 4891-4904. [CrossRef]

22. Dai, J.; Li, G.; Hu, C. Study on a new method to eliminate the common-mode voltage based on improved SHEPWM. In Proceedings of the IEEE 10th Conference on Industrial Electronics and Applications (ICIEA), Auckland, New Zealand, 15-17 June 2015; pp. 1633-1636.

23. Tan, B.; Gu, Z.; Shen, K.; Ding, X. Third harmonic injection SPWM method based on alternating carrier polarity to suppress the common mode voltage. IEEE Access. 2019, 7, 9805-9816. [CrossRef]

(C) 2020 by the authors. Licensee MDPI, Basel, Switzerland. This article is an open access article distributed under the terms and conditions of the Creative Commons Attribution (CC BY) license (http://creativecommons.org/licenses/by/4.0/). 